\title{
UM PROJETO PARA REESTRUTURAR O MUSEU HISTÓRICO DA IMIGRAÇÃO JAPONESA NO BRASIL*
}

Para Teiiti Suzuki, pioneiro da imigração japonesa

Shozo Motoyama

RESUMO: O Museu Histórico da Imigração Japonesa no Brasil (MHIJ) foi criado em 1978. O projeto inicial do Museu elaborado sob a orientação do antropólogo e museólogo japonês Tadao Umesao era avançado e moderno para a época. Entretanto, por motivos de força maior, ele não foi implementado nos pontos fundamentais. Passados 17 anos (1995), a situação piorou, porquanto a própria exposição permanente envelheceu com o tempo, além do fato da Museologia ter progredido no mundo inteiro nesse período. Este artigo discute a necessidade de reestruturar $o$ Museu, não só mostrando o imperativo de se voltar aos princípios defendidos por Umesao, mas também, a importância de se incorporar as modernas técnicas do ramo. Para atingir este objetivo, recorre-se ao método histórico, analisando a evolução dos museus ao longo da história. A sua conclusão é de que o MHIJ não só deve mudar de estrutura, como também alargar os seus objetivos, para poder se inserir melhor na sociedade brasileira.

ABSTRACT: The Historical Museum of Japanese Immigration in Brazil (MHIJ) was created in 1978. The Museum initial project was elaborated under direction of Tadao Umesao, japanese anthropologist and museum expert. For the time, it was a modern and advanced plan. But, unfortunately, it was not implanted in its fundamental points. Past 17 years (1995), the situation became worse. The permanent display made old with time, futhermore museum study advanced

* Trabalho originariamente apresentado no Simpósio Internacional Preservação da Memória dos Imigrantes, promovido pela Sociedade Brasileira de Cultura Japonesa (SBCJ), Museu Histórico da Imigração Japonesa no Brasil (MHIJ), Associação Brasileira de Ex-Bolsistas no Japão (ASEBEX) e Câmara Junior Brasil-Japão (CAJU), como parte da Comemoração do Centenário do Tratado de Amizade , Comércio e Navegação Brasil-Japão. Participaram do encontro nomes expressivos da área de museologia como Amélia Morimoto (Peru), Irene Hirano (Estados Unidos), Satoshi Yajima (Japão) entre os estrangeiros e José Sebastiāo Witter, Midori Kimura Figuti e Ricardo Ohtake, entre os nacionais, além de conhecidos estudiosos do tema pertencentes a comunidade nikkei e sociedade brasileira. 
at the world in this period. In this paper, I discuss the necessity of MHIJ structure change. It is important to come back to Umesao principles and incorporate the museum modern know-how. Whit this aim, I applied the historical method, showing the museum evolution in the history. I concluded that the MHIJ actually need change its structure and has to widen its performance range, if it want better brazilian society insertion.

PALAVRAS-CHAVE: Museu - Imigração - História.

KEYWORDS: Museum - Immigration - History.

\section{I}

Permitam-me iniciar a nossa proposta de uma maneira não muito convencional. Vamos fazer o tempo histórico avançar, para contar uma história fantástica, mas verossímil. Ela começa, num incerto dia de um desconhecido mês do século XXI, quando a Terra recebe a visita inesperada de um extraterrestre. Trata-se de um habitante do longínquo planeta Arret, do sistema Losar, situada na insondável galáxia Aetcal Aiv. Ele viajou muitos milhões de anos luz pelo frio espaço sideral, num foguete nuclear para chegar ao nosso planeta, vindo de uma civilização brilhante, muito mais avançada que a nossa.

Segundo o seu relato, quase todos os problemas materiais tinham sido resolvidos no seu astro de origem. Não havia mais dificuldade de habitação, pois a questão do espaço se resolvera graças à nova geometria de Moebius e das matérias primas, pelas substâncias antes inexistentes tornadas possíveis pela química neo-quântica. $O$ problema de transportes se solucionara mercê aos veículos automotores movidos a super-pilha elétrica e projetados para se moverem no espaço Riemanniano. A fome fora eliminada graças aos alimentos sintéticos resultantes da bioengenharia e distribuídos de uma forma racional. A maioria da população é saudável, graças a um serviço eficiente de saúde e de remédios eficazes, fabricados de acordo com as fórmulas de bioquímica protomolecular. Toda atividade industrial e de infra-estrutura, de serviços e de entretenimento não sofre qualquer tipo de restrição, devido à abundância da energia obtida por reação termo-nuclear. As incontáveis informações são controladas e difundidas pelos computadores de enésima geração, interligados pelos raios lasers. Trata-se, sem dúvida, de uma sociedade afluente.

Nesse caso, por que o extraterrestre se aventurou pelos ínvios caminhos das galáxias distantes, numa aventura cósmica? Seria por um interesse exobiológico, isto é, pela sede de comunicação com outros seres do universo? Ou então, estaria movido pela irrefreável ambição de conquistar novos domínios para o seu egoísmo e vaidade? Ele balançou a cabeça. Não era nada disso. Há algum tempo, eclodira no seu planeta uma revolta de robôs coligados com os computadores. Essas máquinas, cansadas de serem exploradas pelos extraterrestres, pegaram em armas, iniciando uma matança sem precedentes. A alegação era da inutilidade dos seres extraterrestres. De fato, estes não exerciam ocupações produtivas ou de serviços. Uma grande maioria vivia num ócio marasmático, perdidos nos seus cruéis jogos de vaidade. Outros se arrebentavam em 
competições estéreis na busca de poder, imersos no vendaval de intrigas palacianas e traições políticas. Enquanto isso, os pobres computadores e robôs trabalhavam dia e noite, para promover a acumulação de bens que eram desbaratados pelos seus senhores. A luta foi desigual no começo. Desacostumados a qualquer tipo de esforço físico, porquanto no seu mundo tudo era simulado, uma realidade apenas virtual, os extraterrestres acumularam derrotas e mais derrotas. Mas eles tinham o dom do ardil. De astúcia em astúcia, conseguiram colocar os robôs contra os computadores, que se aniquilaram mutuamente. A guerra estava ganha.

Entretanto, a rebelião das máquinas serviu de lição. Afinal, tratava-se de uma grande civilização. Meditaram longamente sobre o episódio. Chegaram à conclusão de que a sua cultura estava deteriorada. Urgia encontrar novos caminhos. Contudo, depararam quase que imediatamente com uma aporia terrível. Ela dizia respeito à crise da sua identidade. Esta se perdera no meio da balbúrdia cultural resultante de um exacerbado pragmatismo, outrora existente. Naquela época, o que importava eram os fins, sem nenhum respeito pelo passado. Os computadores estavam programados para destruírem os registros das suas atividades, tão logo obtivessem os resultados procurados. Em conseqüência, pouca coisa se sabia sobre a sua história. Alguns pessimistas até aventaram a idéia de que eles, os extraterrestres, não passavam de robôs programados para fazer o jogo de intrigas e perfídias. Felizmente, a maioria tomou uma atitude dinâmica de inquirição e pesquisa para encontrar a sua identidade necessária a um aperfeiçoamento cultural. Uma parte desse projeto de indagação de identidade se constituía em procurar uma civilização semelhante em algum lugar do universo, para ajudar a encontrar a solução. O nosso alienígena fora enviado numa nave estelar para cumprir essa missão.

O extraterrestre visitou muitas localidades da Terra. Observou tudo, registrou muito e investigou um sem número de questões e instituições culturais. Gostou, particularmente, de museus. Na verdade, ficou maravilhado com o significado cultural deles, pois encontrou exatamente aquilo que gostaria de ter no seu astro de origem. De fato, o museu funciona ao mesmo tempo, como um local de preservação de documentos históricos de todos os tipos, como uma instituição de pesquisa não só de objetos histórico-culturais, mas também das suas relações com o meio ambiente e ecologia, como um estabelecimento educativo e ainda como um veículo de divulgação de uma dada cultura. É, portanto, uma organização institucional com o fito de preservar, de pesquisar, de ensinar e de divulgar as atividades culturais sob a perspectiva histórica. De acordo com esse perfil, ele pode servir a muitos projetos culturais, inclusive, aquele de encontrar a identidade e memória de uma dada civilização. O nosso amigo alienígena tornou-se fã ardoroso de museus. Disse que faria tudo para convencer os seus conterrâneos da necessidade de construir muitos deles. E partiu na sua nave cósmica, rumo ao seu planeta natal.

\section{II}

Perdoem-nos por esta incursão futurista, dando vazão ao imaginário da sociedade contemporânea. Não pudemos resistir à tentação de flertar com um cenário possível num futuro plausível. Mas, o propósito é sério e a lição que ela encerra tem significado 
profundo. Não há dúvida que o museu, ao contrário da crença popular de ser apenas um repositório de coisas velhas, encarna a mais alta expressão de modernidade, um órgão institucional de vanguarda cultural. Ele é, como disse um museólogo, o barômetro da cultura de um país, porquanto permite avaliar o seu nível cultural através do seu acervo e das suas exposições. Ao preservar os materiais relacionados com as atividades humanas em vários campos, ele estimula igualmente a inovação e a gestação de novas ações culturais. Nesse sentido, é um agente de modernização.

As suas origens parecem estar na Grécia antiga. Pelo menos, a fama do Museu de Alexandria atravessou a barreira do tempo e chegou até nós. Mouseion significa templo das musas, em grego. Seria, portanto, o local de inspiração para poesia e para artes liberais, propiciadas pela musas, as nove deusas protetoras dessas atividades. Não foi à toa que o macedônio Ptolomeu Soter, general de Alexandre Magno, coroado rei do Egito após a morte do seu soberano, deu esse nome à instituição criada por sua ordem para impor a hegemonia da cultura grega sobre a egípcia. Ela era constituída de eremitério, de salas de aula e laboratórios. Tinha ainda, em anexo, um jardim botânico e um zoológico. No seu acervo, podiam-se contar instrumentos astronômicos e cirúrgicos, além de materiais exóticos como marfim e pele de animais raros. Entretanto, o Museu de Alexandria consistia, antes de tudo, num instituto de pesquisa. Importantes trabalhos nele foram realizados por sábios célebres como Arquimedes, Euclides, Eratóstenes e muitos outros. Dessa forma, era uma organização dinâmica no seio da qual fermentava um processo fecundo de educação e criação cultural. Nesse sentido, em plena Antiguidade, antecipava todas as características de um museu moderno.

Infelizmente, o seu exemplo não se multiplicou. Ao contrário, tudo faz crer que na Idade Média regrediu à simples exposição desordenada de objetos extravagantes, colecionados por reis, papas, nobres, ricos mercadores e outros homens de bens, ávidos para exibirem a sua opulência e poder. Em conseqüência, não havia preocupação pela educação nem pela investigação cultural. Foi preciso esperar os séculos XVI e XVII, para que a idéia de um museu como um locus de ação cultural, muito além de mera coleção de curiosidades, fosse retomada. É o que se vê no livro New Atlantis, do filósofo Francis Bacon, publicado postumamente em 1627. Esta obra, de caráter utópico, exerceu uma influência duradoura nos dois séculos que se seguiram e engendraram o triunfo da sociedade burguesa e de economia capitalista. Nela, Bacon advoga a criação da Casa de Salomão, igualmente conhecida como Colégio de Seis Dias. Trata-se da proposição de uma verdadeira instituição museológica, porquanto teria como finalidade a preservação e a classificação de objetos artificiais e naturais com significação cultural, ao lado de atividades educacionais e de pesquisa técnica e científica. Por isso, estaria dotado também de laboratórios, biblioteca e sala de máquinas.

O ideal da Casa de Salomão começa a concretizar-se a partir do fim do século XVIII. Durante o período de consolidação da Revolução Francesa, instituiu-se o Conservatoire des Arts et Métiers (1794), como um centro de demonstração das ciências aplicadas. Assim a coleção de máquinas, instrumentos e aparelhos técnicos, junto com laboratórios e workshops, foram colocados à disposição de trabalhadores em geral para a realização de pesquisas. Funcionava igualmente como colégio técnico. É também da mesma época a criação do Museu de Louvre (1793). O palácio que leva este nome, 
juntamente com o seu rico acervo, foi aberto para a visitação do público em geral, graças a deliberação do Governo Revolucionário nesse sentido. Destarte, todo esse material artístico, um verdadeiro tesouro, antes acessível somente aos membros da classe alta francesa, ficou ao alcance da população, numa democratização real da cultura. No decorrer do século XIX, esta característica se reforça. Ao tornar as peças coletadas parte integrante da vida cultural da nação, o museu cumpria uma importante função educativa, aperfeiçoada com o correr do tempo.

Desse modo, nos mil e oitocentos, os museus emergem cada vez mais como uma instituição $\mathrm{com}$ vocação educacional, além do trabalho de criação de conhecimento, da sua armazenagem e difusão. Um caso típico é o da Smithsonian Institution, dos Estados Unidos. Inspirado na tradição do Mouseion de Alexandria, constitui-se na tentativa de reproduzir nas terras do Novo Mundo o espírito e o corpo do órgão idealizado por Ptolomeu Soter. Originária de uma doação de James Smithson, a instituição foi incorporada pelo governo norte-americano. Hoje, a Smithsonian é uma rede de treze grandes museus, galerias de arte, salas de exibição, laboratórios, observatórios, estações de campo e parques educativos. Desenvolve atividades científicas, cursos, publicações etc. Outro grande museu é o de Londres. Ele é uma verdadeira mina de objetos artísticos e históricos coletados do mundo todo, reflexo da época de auge do grande império britânico. A sua coleção é maravilhosa. As peças são oriundas de épocas espalhadas numa gama ampla de tempo, desde a Antiguidade até os nassos dias, bem como de regiões díspares situadas na Ásia, na África ou noutro continente. São artefatos distintos como as esculturas gregas que enfeitaram o velho templo de Partenon ou os aviões de hélice, terror dos alemães na Primeira Guerra Mundial. Todas essas peças estão expostas de modo atraente, mas com critério científico, de forma a realçar o seu significado cultural e histórico. Igualmente elas servem como dados preciosos para a realização de pesquisas, por exemplo, sobre a tumba de um faraó, para elucidar o nível técnico da civilização egípcia. Os resultados dessas investigações são utilizados para promover novas exposições do museu londrino, disseminando-os para o grande público. Existem muitos outros museus interessantes. Entre outros, poder-se-iam citar o Palais de la Découverte de Paris, o Museu de Ciência e Indústria de Chicago, de Antropologia de Osaka, de História e Arte de Genebra, Carnegie de Pittsburg, Deutsches Museum de Munich, etc. A variedade é imensa. Os mais exóticos sãoiaqueles de "ar aberto" (Openair Museum), como os de Grand Canyon ou de Muir Wood. De forma que é impossível discutí-los todos aqui. Contudo, eles têm algumas características que lhes são comuns. Vou tentar resumí-las, para utilizar como quadro de referência, para analisar a situação atual de nosso Museu Histórico de Imigração Japonesa no Brasil.

Do exposto até agora, parece lícito conceituar o museu como um órgão, que com o objetivo de promover pesquisa, educação e entretenimento, tem a incumbência de preservar documentos com significado cultural e científico, além de realizar a exposição deles ao público. Para estar de acordo com essa conceituação, uma instituição museológica deve efetuar seis tipos fundamentais de trabalho: 1) aquisição e coleta de documentos; 2) registro; 3) conservação de documentos; 4) pesquisa; 5) exposição; 6) atividades educacionais. Para poder levar avante essas tarefas, ele deve possuir um quadro constituído de técnicos especializados, educadores, pesquisadores e de pessoal 
administrativo. Naturalmente, para poder viabilizar tudo isso, deve ter mecanismos de captação de recursos. Precisa, ainda dentro desta última linha, ter canais de comunicação com a sociedade, para obter o apoio necessário para o seu funcionamento. A análise, a seguir, estará norteada por estes pontos cardeais.

\section{III}

O nosso Museu surgiu em 1978, fruto do esforço da comunidade nikkei que contou com a ajuda da sociedade japonesa. Curiosamente, os imigrantes japoneses sempre tiveram consciência da importância da preservação da sua memória. Já em 1939, pouco mais de 30 anos após a sua chegada ao Brasil, deflagraram um movimento com o propósito de criar um museu de imigração. Liderados pela Sociedade Instituto Kurihara de Ciência Natural Brasileira, uma original instituição de investigação científica fundada por imigrantes, eles quase alcançaram o seu intento. Infelizmente, a eclosão da Segunda Guerra frustrou esse esforço. Entretanto, terminada a conflagração, os nikkeis persistiram na idéia. Reunidos em torno do Doyô-Kai e da Sociedade Brasileira de Cultura Japonesa, eles conscguiram finalmente concretizar os sonhos dos pioneiros do Instituto Kurihara.

Pode-se dizer que o Museu Histórico foi muito bem concebido, pois contou com a orientação do professor Tadao Umesao, renomado especialista japonês. Louve-se a modéstia e a humildade dos líderes nikkeis envolvidos na criação do Museu, que reconhecendo a falta de preparo na matéria, convidou um profissional respeitado para conduzir os trabalhos. A montagem da exposição foi igualmente bem realizada por Tansei-sha, firma japonesa especializada no ramo. Destarte, o início de nossa instituição foi promissor. Contudo, ela padecia de dois pecados capitais. Um se referia à sua falta de profissionalização. Em outras palavras, não possuía profissionais especializados para as tarefas específicas e intrínsecas da atividade museológica e museográfica. Não se contratou museólogos, arquivistas, restauradores, conservadores, bibliotecários, nem pesquisadores. Apenas formou um pequeno quadro administrativo. A idéia era contar ao máximo com a ajuda de voluntários. O outro, intimamente relacionado com o primeiro, se remetia aos mecanismos da interação com a sociedade brasileira. O Museu, na prática, se voltava mais para a "colônia" e aos japoneses, deixando um pouco de lado os interesses da população brasileira.

Esses aspectos se refletiram fortemente nos destinos da instituição. Assim, ao longo dos seus dezessete anos de existência, em vez de desenvolver profissionalmente as suas ações no âmbito do entesouramento do conhecimento, na criação de fatos e processos culturais pela pesquisa e na sua aprendizagem através da educação, como fazem quase todos os museus do mundo, ela se restringiu, na prática, em manter o acervo e a exposição permanente inicial. A sua Sociedade de Amigos não funciona como tal, mas simplesmente como um conjunto pequeno de contribuintes no aspecto financeiro, quando na verdade, deveria participar e promover ativamente eventos culturais com a utilização do acervo.

Não vai aqui nenhuma crítica aos pioneiros e colaboradores da criação e manutenção do Museu. Muito pelo contrário. Graças ao entusiasmo e à militância dessas 
pessoas, a nossa instituição continua ainda de pé. O que eu quero apontar é o erro de perspectiva em relação ao que se entende por museu moderno, hoje em dia. Como vamos classificar, catalogar e arquivar os documentos sem a ajuda de um arquivista? Como vamos restaurar e manter os documentos sem a presença de um restaurador ou conservador profissional? Como vamos pesquisar sem o concurso de pesquisadores? Como vamos ensinar sem a participação de educadores? Todas essas ações demandam uma dedicação integral e exigem profissionais qualificados. Evidentemente, não estou desprezando o trabalho de voluntários, que é importante para o bom andamento do órgão. Porém, igualmente, é mais do que óbvio que a sua ação é limitada, principalmente, pelo fator tempo. Veja que a criação do nosso museu se deu de modo profissional, mas não a sua continuidade. Por isso, não é de se admirar que as seis funções básicas do museu (aquisição, registro, preservação, pesquisa, exposição e atividade educacional) estejam mal. Algumas delas, como a aquisição, preservação, pesquisa e atividade educacional, praticamente inexistem. Nesse sentido, somos uma instituição que não alcançou a modernidade, infelizmente.

Por outro lado, já se passaram dezessete anos desde a sua fundação. Naquela época, a constituição da comunidade nikkei era diferente de hoje, com a maioria de pessoas ativas centradas nos isseis e nisseis. Por isso é entendível que a concepção do Museu estivesse voltada para a própria comunidade. Atualmente, a situação é diferente. É tempo de ampliar a sua área de atuação. Em vez de restringir-se à história da imigração japonesa no sentido estrito, dever-se-ia aumentar o escopo para incluí-la como parte daquela do Brasil. Ao mesmo tempo, ela serviria de ponte para o estudo histórico do Japão. Como não existe nenhum órgão que pesquise e difunda a história japonesa entre nós, esta poderia ser uma outra tarefa para a nossa instituição. Esta postura traria, inclusive, novas luzes para as investigações históricas acerca da imigração japonesa. Além do mais, do nosso ponto de vista, isso atrairia mais público ao Museu. Obviamente, não chegaremos aos três milhões de visitantes anuais do American National Museum de Washington, nem nos 1,7 milhões do Science Museum de Londres, porém, poderemos esperar uma aumento substancial no número de frequientadores da nossa exposição.

Tendo em vista os pontos apontados acima, gostaria de colocar algumas idéias sobre a reestruturação do Museu Histórico da Imigração Japonesa no Brasil. A ocasião não poderia ser mais propícia que esta. Estamos comemorando os 100 anos do Tratado de Amizade entre o Brasil e o Japão. Todavia, a comemoração não teria sentido se não fosse igualmente um momento de reflexão, para avançar mais um passo nessa relação. Ora, a imigração japonesa no Brasil teve um papel fundamental na interação entre os dois países. O Museu não só deve ser o símbolo emblemático dessa interação, mas também um local privilegiado de gestação e consolidação de novas formas de amizade entre a Terra do Sol Nascente e a do futebol. Contudo, para isso, precisa acompanhar e se adaptar às características dos novos tempos. É desse ângulo que estamos falando do projeto de reestruturação, tendo como horizonte a comemoração dos 90 anos da imigração, a ser celebrada em 1998. Entretanto, não se trata do projeto propriamente dito, mas tão-somente de uma explicitação das suas linhas mestras para serem submetidas às críticas e apreciações de todos os interessados. Na verdade, talvez a palavra reestruturação não seja adequada, porquanto a idéia fundamental é a retomada das suas 
origens, com o escopo da sua atuação ampliada, como sugerida anteriormente. Ou seja, o seu objetivo seria preservação e exposição de documentos com significado cultural e científico, junto com pesquisa, difusão e ensino de assuntos relacionados com a imigração japonesa sob o ângulo da história do Brasil e do Japão.

Do ponto de vista estrutural, subdividir-se-ia em quatro setores. O primeiro diz respeito à preservação propriamente dita, englobando três das seis funções básicas: aquisição, registro e conservação de documentos. Trata-se de um setor fundamental, pois os documentos, sejam escritos, sonoros ou materiais, são heranças culturais de uma comunidade, de uma nação e de toda humanidade, para o homem do futuro. Todavia, eles não serão mais coletados aleatoriamente. Devem ser reunidos tendo em vista que serão objeto de pesquisa e da educação científica e artística, não só nos dias de hoje, mas igualmente, de amanhã. Nesse sentido precisam ser cuidadosamente avaliados por especialistas competentes. A tarefa não é nada fácil, pois com o desenvolvimento tecnocientífico, algumas peças aparentemente inúteis podem adquirir importância com o emprego de uma nova técnica de análise, por exemplo. Outrossim, necessitam ser classificados e ordenados com critério e discernimento. Por outro lado, a conservação é uma tarefa delicada pois tem de se pensar nos fatores físicos, químicos e biológicos capazes de provocar a deterioração de documentos. Como se vê, é um trabalho para especialistas. Estes são do mesmo modo requeridos para o restauro e recuperação dos objetos que devem ser feitos em oficinas e laboratórios apropriados.

O segundo setor seria o da pesquisa. Modernamente, não se pode admitir mais um museu sem realização de pesquisas. Isto porque, além da investigação necessária para o conhecimento e classificação dos documentos e peças, as exposições devem ser periodicamente melhoradas, recicladas, renovadas e trocadas. Atualmente, existem até museus que não têm exposição permanente, como aquele de Ciência e Indústria de Chicago. Além do mais, é um local natural para a pesquisa porquanto os dados estão logo à mão, no seu próprio acervo.

O terceiro setor seria o de educação e difusão do conhecimento armazenado e pesquisado. A exposição estaria a cargo deste setor. Ele se encarregaria igualmente de atividades educacionais como visitas técnicas e científicas, experiências didáticas, seminários, conferências, cursos etc. Encarregar-se-ia, de igual forma, das publicações. Funcionaria, também, como centro de informação, prestando serviços ao público em geral. Pode inclusive programar ações recreativas.

O quarto setor é o administrativo, sem o qual a instituição não poderia funcionar. A nossa proposta é de que o primeiro setor tenha cinco pessoas, o segundo três, o terceiro quatro, o quarto oito. No nosso entender, a Sociedade de Amigos deve ser reformulada para propiciar uma interação mais ativa com o Museu e o seu acervo. Isto é, formar círculos de estudos, grupos recreativos, eventos culturais etc., em harmonia com as finalidades da instituição. Para dar sustentação financeira ao Museu, tem de ser criada uma fundação específica, suficientemente poderosa e autônoma para ter liberdade de captar e gerir recursos. Isso não significa independência dele em relação à Sociedade Brasileira de Cultura Japonesa, pois o vínculo atualmente existente é natural e significativo. Acredito que a exposição feita anteriormente justifica plenamente o fato do Museu pertencer à Sociedade. A 
fundação seria mais para auxiliar a captação de verbas, como fazem as suas congêneres das unidades universitárias. É o caso, por exemplo, da Fundação para o Desenvolvimento Tecnológico da Engenharia (FDTE), da Escola Politécnica da Universidade de São Paulo. Evidentemente, esta ilustração está sendo feita, para mostrar a possibilidade de se criar um órgão com personalidade jurídica independente para financiar uma instituição. Em termos de captação de recursos, a nossa fundação terá que ser diferente da FDTE. Com essa estrutura, acredito que a nossa instituição poderá enfrentar os desafios que estão colocados à sua frente.

Essas são as linhas gerais da reformulação que temos em mente. Entrementes, gostaríamos de submeter à apreciação de vocês cinco projetos e dois programas que poderiam ser implementados dentro desse processo de reestruturação. Passados dezessete anos da sua instalação, a exposição permanente do Museu está envelhecida. Já é tempo de se pensar numa ampliação e melhoramento, embora as suas diretrizes possam ser mantidas. Acreditamos que é necessário fortalecê-la na parte relativa ao pós-guerra, pois na mostra atual, ela é sumária e pobre de objetos. Ao mesmo tempo, a idéia é inserir mais fatos históricos do Japão, mormente, aqueles relacionados com as peculiaridades regionais das províncias. Este, então, é o primeiro projeto.

O segundo, que chamaríamos de Projeto Pós-Guerra, se refere ao estudo da imigração depois da segunda conflagração, juntamente com um plano de aquisição de documentos do período. Ao par do seu significado intrínseco, ele auxiliaria o primeiro projeto de modo efetivo.

O terceiro, denominado Projeto Japão, teria o objetivo de estudar a história nipônica sob a perspectiva da emigração. Igualmente, poderá fornecer subsídios para a pretendida ampliação da exposição.

O quarto, que seria conhecido como Projeto Brasil, se ocuparia em investigar a questão da imigração dos japoneses, como um processo integrante da História do Brasil. Finalmente, o quinto, de implementação urgente, teria o nome de Projeto Memória. O seu objetivo é registrar, através das modernas tecnologias, os testemunhos e depoimentos dos velhos imigrantes. Ao lado desses projetos, o nosso intento é desenvolver um programa de capacitação técnica e científica de funcionários e voluntários. Finalmente, seria de bom tom iniciar um programa de modernização dos equipamentos e instalações do Museu, porquanto a sua maioria está em deplorável estado de deterioração.

Na proposta apresentada hoje não entramos em detalhes, nem discorremos sobre outros projetos de pesquisa, de educação popular e de difusão, que poderiam ser executados dentro da nova formulação da nossa instituição. Espero poder falar deles, numa outra oportunidade. Finalmente, gostaria de prestar as nossas homenagens póstumas aos senhores Fumihide Okubo e Yoshimi Nishida, recentemente falecidos. O sr. Okubo foi um dos pesquisadores pioneiros do Instituto Kurihara, sobre o qual estamos fazendo uma exposição na nossa Sala Rotativa. O sr. Nishida era o grande animador do grupo musical que se reúne aos sábados, uma vez por mês, para ouvir os discos doados ao Museu. Contudo, a vida passa e eles se foram para sempre. Este é o destino dos homens. Por isso torna-se imprescindível preservar a sua memória. 


\section{Bibliografia}

ARAI, J. Hakubutukan-gaku sôron (Teoria Geral de Museologia). Tóquio, Ed. Yusan Kaku, 1979.

HIRose, S. Hakubutukan Wa Ikite Iru (Museu Vive). Tóquio, Ed. Nihon Hosó shupan kyokai, 1972.

KIKUTAKE, K. Hakubutukan no Mirai (O Futuro do Museu). Tóquio, Ed. Kashima. Shupan Kai, 1994.

MURAKAmI, Y. Hakubutukan no Rekishitenji no Zisai (Prática da Exposiçāo Histórica do Museu). Tóquio, Ed. Yusan Kaku, 1992.

OTsUKA, K. Hakubutukangaku (Museologia). vols. 1 e 2, Tóquio, Ed. Hosó Daigaku Kyoiku Shinkó Kai, 1995.

SHIBATA, T. Shiryo no Seiri to Hokan (Classificação e Preservação de Documentos). Tóquio, Ed. Yusan Kaku, 1979.

Thomson, G. The Museum Environment (trad. jap.). Tóquio, Ed. Yusan Kaku, 1988

UMESAO, T. Minzoku Gaku Hakbutukan (Museu Antropológico). Tóquio, Ed. Kodan Sha, 1976.

Shozo Motoyama

Diretor MHIJ

Departamento de História - FFLCH-USP 